\title{
Minimalism and Expressivism
}

\author{
Fritz McDonald (Oakland University)
}

There has been a great deal of discussion in the recent philosophical literature of the relationship between the minimalist theory of truth and the expressivist metaethical theory. The minimalist theory of truth, developed by Paul Horwich (1998) is a theory of truth the central theses of which are: The meaning of 'true' is explained fundamentally by the acceptance of a trivial schema T:

$\mathrm{T}:<\mathrm{p}>$ is true iff $\mathrm{p}$.

(In the schema, ' $\langle\mathrm{p}\rangle$ ' is short for 'the proposition that p.'). The purpose of the notion of truth is to allow the formulation of generalizations such as 'Everything the president said was true' and 'All instances of ' $p$ or not $p$ ' are true'. Truth is a property, but it is not a substantial property of the sort that does explanatory work (beyond the fact of acceptance of the truth schema).

One group of philosophers contends that this minimalist theory of truth and metaethical expressivism are compatible, the other group contends that such theories are incompatible. I will call the former position 'compatibilism' and the latter position 'incompatiblism.' The claim that there is such an incompatibility, I will argue, is based on a misunderstanding of the historical roots of expressivism, the motivations behind the expressivist theory, and the essential commitments of expressivism. I will present an account of the expressivist theory that is clearly consistent with minimalism. It is important to note that this is not simply, as it may first seem, a verbal dispute regarding the proper uses of the terms 'minimalism' and 'expressivism.' Any such dispute would be of little theoretical interest. The concern 
that I will address in this paper is a substantive one. Opponents of the compatibilist position have incorrectly overlooked a possible philosophical position. Regardless of the labels applied to such philosophical positions, the very possibility of these positions being correct ought not to be denied without sufficient argument and consideration of the complete array of metaethical views in logical space.

\section{Are Minimalism and Expressivism Compatible?}

Paul Boghossian (1990), Crispin Wright (1985, 1992, 1996), and John Divers and Alexander Miller (1994) have argued that the minimalist account of truth is incompatible with the expressivist theory of morality, the proponents of which traditionally have held that moral utterances are neither true nor false. The apparent difficulty here results from the view that the expressivist, in order to distinguish her view from those who hold distinct metaethical positions, must hold the view that moral utterances are neither true nor false. I will call this view of moral truth the 'Denial Thesis.' Philosophers whose views were ancestors of expressivism, such as David Hume and A.J. Ayer ${ }^{1}$, have held the denial thesis, as well as (in certain writings) recent expressivist writers such as Allan Gibbard (1990).

The apparent trouble with squaring expressivism with minimalism is that there is only a trivial difference, on such theories, between the assertion that $p$ and the assertion that it is true that $\mathrm{p}$. In discussions of moral matters, it is quite clear that utterances that have the appearance of genuine assertions are made, and such apparent assertions would seem to express true or false propositions regarding moral issues. A person may sincerely assert "Great inequalities in the distribution of wealth are unjust," and such an ostensible assertion would seem to express the belief that great inequalities in the distribution of wealth are unjust.

However, given that the object of this apparent belief is the proposition that great inequalities in the distribution of wealth are unjust, the minimalist would have to accept that such a proposition is capable of being straightforwardly true or false, pace the traditional expressivist view. It may still be possible for a minimalist to deny that there are in fact propositions expressed by these apparent assertions of moral claims. The most coherent position for a minimalist to hold is one according to which there are moral propositions, and thus moral utterances are capable of being true or false: In order to deny this, a minimalist would have to claim that these utterances do not have a propositional content, a meaning, and such statements do not seem to be meaningless.

\footnotetext{
${ }^{1}$ I am not here claiming that Hume or Ayer is an expressivist in the contemporary sense.
} 
According to the view that moral utterances have propositional contents, the following would be a legitimate instance of the minimalist schema:

I: $<$ Great inequalities in the distribution of wealth are unjust $>$ is true iff great inequalities in the distribution of wealth are unjust.

Thus, according to a minimalist account of truth, given the further assumption that moral utterances genuinely express propositions, such utterances must be either true or false. Such an admission is tantamount to the rejection of traditional expressivism.

There are a number of reasons to think that rejecting this aspect of traditional expressivism would be a good thing. The claim that normative and moral utterances are incapable of being true or false does not fit well with ordinary practice. Speakers commonly attribute truth or falsehood to moral utterances. People generally consider utterances of 'Rape is wrong' true, and consider utterances of 'It is permissible to attack strangers for fun' false. Any philosophical qualms regarding the attribution of truth (or falsehood) to moral utterances do not seem to affect this practice of attributing truth values to moral utterances.

There are number of related factors that tell in favor of the attribution of truth to moral utterances. Normative and moral assertions also have all of the same surface features as nonnormative and nonmoral assertions. Attributions of truth to moral utterances would be required to account for the role such utterances play in valid arguments. In order to have the possibility of a notion of moral knowledge that accords well with our ordinary practice, we would need to attribute truth to moral utterances.

While minimalism would allow the expressivist to attribute truth to moral utterances, the aforementioned incompatibilist philosophers have held that expressivists who accept minimalism do so at the cost of their own theory. In "The Status of Content," Boghossian presents a version of this incompatibilist argument directed toward the work of A.J. Ayer. Boghossian summarizes Ayer's account of the redundancy theory of truth and his emotivist account of ethics, and claims that Ayer failed to recognize

the tension between such a [redundancy theory] conception [of truth] and a nonfactualist thesis about a given range of assertoric discourse (Boghossian 1990, 163).

The particular "non-factualist thesis" Boghossian has in mind here is Ayer's emotivist account of moral discourse.

Boghossian notes correctly that moral utterances fit many of the criteria for straightforward assertoric discourse of the sort to which one would attribute truth. Moral utterances are meaningful, declarative, and are embedded in sentences formed by truth functional connectives (conjunction, disjunction, negation, 


\section{2 | Fritz McDonald}

conditionals) and within propositional attitude contexts. There is at least a prima facie reason to regard such utterances as being on a par with nonmoral utterances.

Given that we have such good reason to attribute truth to moral utterances, Boghossian contends that Ayer's redundancy theory and expressivism are in conflict. In order to resolve the conflict, one needs a more "robust" theory of truth that will allow one to distinguish moral discourse, which is neither straightforwardly true nor false, from other realms of discourse that can be straightforwardly true or false (such as, for example, physics). Boghossian writes:

A non-factualism about any subject matter requires a conception of truth stronger than the deflationary: it is committed to holding that "true" stands for some real, languageindependent property, eligibility for which will not be certified solely by the fact that a sentence is declarative or significant (Boghossian 1990, 165).

It is important to note here that this argument is framed in response to Ayer's views. Boghossian (1990) objects to deflationary theories of truth on the grounds that a "nonfactualist" account of truth cannot distinguish between factualist and nonfactualist accounts of different discourses. One aspect of this argument is that certain deflationists cannot explain the use of the notion of truth to generalize over claims in a given discourse. This objection is not successful against minimalism regarding truth. Unlike earlier deflationary theories such as the redundancy theory of truth, minimalism allows that 'true' is a genuine predicate and truth itself is a property. As a result minimalism is not susceptible to this aspect of Boghossian's argument. The question still remains whether, on a minimalist account, one can mark a distinction between factual and nonfactual discourse.

The argument presented by Wright differs from that of Boghossian insofar as it is clearly directed at contemporary deflationists. Wright argues that any expressivist or projectivist account that allows for the attribution of truth to moral utterances will collapse into moral realism. In his review of Spreading the Word, Wright makes this charge against Blackburn's quasi-realism. While not explicitly mentioning deflationism or minimalism, Wright notes that Blackburn's account seems to pave the way for the attribution of truth to moral statements, a result that deflationists and minimalists ought to accept. Thus Wright is dubious of the compatibility of the attribution of truth to moral claims and expressivism:

If it really can be explained - and Blackburn takes imaginative strides toward doing sohow the moral projectivist can acknowledge the susceptibility of moral judgements to conditional and other forms of embedding, and even how we can have a worthwhile truth predicate for them, then, so far from vindicating a form of moral anti-realism, why has it not been explained how the moral realist can, in effect, cut past the epistemological difficulties which beset non-naturalism without incurring any obligations to furnish reductions? (Wright 1985, 318). 
I will call this argument of Wright's the 'collapse argument.'

A more recent version of the collapse argument is clearly directed at minimalism regarding truth ${ }^{2}$. Wright contends that minimalism undermines both expressivism and the error theory of J.L. Mackie (1977):

With each of these minimalisms in place, almost all of the areas which have traditionally provoked realist/anti-realist debate-ethics, aesthetics, intentional psychology, mathematics, theoretical science, and so on-will turn out to traffic in truth-evaluable contents, which moreover, when the disciplinary standards proper to the discourse are satisfied, we are going to be entitled to claim to be true. So two traditional anti-realist paradigms are immediately under pressure: expressivism-the denial that a target discourse, despite an apparently assertoric surface, really deals in truth-evaluable contents-is not going to be an option; and the error-theorist, like John Mackie on ethics...will have his work cut out to make the charge of global error stick... (Wright 1996, 864).

The collapse argument can be paraphrased without using the somewhat vexed jargon Wright uses. One of the main points Wright is making regarding expressivism is as follows:

1. In order for expressivism to be a distinct philosophical position, there must be a significant difference between expressivism and moral realist positions.

2. The only significant difference there could be between expressivism and moral realism is the different approaches taken by the expressivist and the moral realist to the attribution of truth to moral utterances.

3. On the assumption that a deflationist or minimalist account is correct, then the expressivist ought to attribute truth to moral utterances in the same fashion as the moral realist.

4. Thus, on the assumption that a deflationist or minimalist account is correct, expressivism is not a distinct philosophical position.

The problematic premise in this argument is premise 2. There is at least one significant difference between the expressivist and the moral realist, namely, a difference in their view of moral ontology. Distinguishing the expressivist and the

\footnotetext{
2 It is worth noting that Wright uses the term 'minimalism' to refer to a different theory from the minimalist theory of truth I have discussed throughout this paper. The characteristics of Wright's 'minimalism' and the minimalist theory of truth that lead to the problem discussed here are identical, though, and hence it is reasonable to take Wright to be criticizing not only 'minimalism' (in his sense) but all deflationist and minimalist accounts of truth. Also, Wright claims that 'minimalism' (in his sense) is what all deflationary theories essentially amount to, or ought to be: “...minimalism about truth, as described in this and the succeeding chapter...is just what the deflationist trend comes to (what would-be deflationists like Horwich ought to advocate)" (Wright 1992, 12). For this reason, it will not be necessary for the purposes of this paper to go into great detail regarding Wright's 'minimalism' and the differences between it and deflationary accounts when taking into consideration Wright's arguments.
} 
realist on these grounds has not been the standard approach in the metaethics literature.

\section{The Collapse Argument and the Semantic Strategy}

One possible response to Wright's collapse argument is to suggest that the distinctive account offered of moral semantics by expressivists such as Blackburn (1998) and Gibbard (2003) is the element of expressivism that distinguishes expressivists from realists. It is this semantics that, contrary to premise 2 of the collapse argument, provides for a distinction between expressivist and realist views. James Lenman (2003) contends that the distinctive element of expressivism is its semantic view. Certain sentences in a language, according to Lenman, are truth-apt without further explanation. An example of such a sentence, according to Lenman, is "Everest is higher than Snowdon." What is distinctive about an expressivist account of discourse is that such an account explains the truth-aptitude of the relevant sentences in terms of the semantics of non-truth-apt sentences. To use Lenman's examples, the truth-apt sentence L1 has a meaning that, on an expressivist account, is spelled out based on the meaning of non-truth-apt sentence L2:

L1: It is wrong to kill innocent people.

L2: Hurrah for our not killing innocent people! (Lenman 2003, 57).

This marks out a distinction between sentences with simple truth-aptness such as "Everest is higher than Snowdon" and sentences with explained truth-aptness such as L1.

Does this contrast between sentences that are simply truth apt and those sentences that have an explained truth-aptness mark a difference between expressivists and realists? Is this sufficient to answer Wright's collapse argument? It is hard to see how this would be so. Lenman's semantic strategy may serve well as an account of a key element of expressivist accounts of discourse, but this strategy does not provide for a distinction between expressivists and realists. This is so, because it would be perfectly possible for a full-blown Moorean realist to agree with the expressivist on the explanation of the semantics of sentence L1, while still holding that moral realism is nonetheless correct. One could both be a nonnaturalist realist like G.E. Moore, believing that there exist non-natural moral facts, while also accepting semantics of the sort suggested by Lenman. A focus on semantics is beside the point of what distinguishes expressivists from realists, given that the latter is not primarily a semantic doctrine but a metaphysical one. For this reason, the semantic strategy alone is insufficient to answer the concern raised by Wright. 


\section{The Collapse Argument and Moral Ontology}

As noted above, the significant difference between the moral realist and expressivists is the distinctive account offered by expressivists of moral ontology. Expressivists have motivated their view by noting the distinctions between the metaphysical commitments of expressivism and realism. Blackburn, in his "How to be an Ethical Antirealist," characterizes his "projectivist" view as an "antirealist" one due to the fact that such a theory involves explanations of moral matters that need not make appeal to moral facts and properties:

This theory is visibly antirealist, for the explanations offered make no irreducible or essential appeal to the existence of moral "properties" or "facts"; they demand no “ontology of morals" (Blackburn 1988, 174).

Gibbard distinguishes, in Wise Choices, Apt Feelings, between naturalistic facts, normative facts, and facts of meaning. Gibbard then claims that there are no real normative facts: "In my own picture... [apparent] normative facts, will come out, strictly, as no real facts at all..." (Gibbard 1990, 23). In his recent book Thinking How to Live, Gibbard characterizes expressivism as denying that there are any distinctive normative states of affairs:

There is no such thing as a specifically normative state of affairs; all states of affairs are natural...Then, clearly if my quasi-realism is correct, there aren't distinctively normative facts, only naturalistic facts (Gibbard 2003, 181).

How are we to understand this key metaphysical component of expressivism, the idea that there are no "irreducible," "essential," or "specifically normative" properties or

facts? One might suspect at this point that the minimalist is in a poor position to do so-as James Dreier has suggested recently, there is an apparent problem of "creeping" minimalism (Dreier 2004). Minimalists who have been inclined to accept the minimalist truth schema have also been inclined, on similar grounds, to accept a minimalist property schema, a schema that claims that properties are the "shadow" of predicates. In his discussion of Gibbard's Wise Choices, Apt Feelings, Horwich has suggested the following property schema:

For any object $x, x$ has the property of being $F$ if and only if $x$ is $F$. (1993, p. 74). If this is the proper minimalist approach to properties, then any theorist who accepts the appropriateness of assertions involving moral predicates will also accept the existence of moral properties: there is only a trivial step from 'Inequality in wealth is wrong' to 'Inequality in wealth has the property of being wrong.'

Horwich offers similar minimalist schema for the proper understanding of facts, in general. According to following minimalist fact schema, 
That $p$ is a fact if and only if $p$ (Horwich 1993, 74).

This fact schema, like the property schema, seems to deflate entirely the ontological dispute over moral realism and moral antirealism. Any philosopher who would accept the truth of a first-order moral claim such as 'Inequality in wealth is wrong' would be committed as well, by the fact schema, to 'It is a fact that inequality in wealth is wrong.' Thus it seems that the minimalist is committed to the existence of moral facts and properties, and there is no significance to the dispute between moral realists and expressivists. This is the "problem of creeping minimalism." If this indeed happens to be a problem without a solution, it would seem to vindicate Wright's claim that expressivists, without the denial thesis, cannot mark a distinction between expressivism and realism.

Dreier does not claim that the problem of creeping minimalism cannot be solved - He has suggested that there is, even taking a minimalist approach to properties and facts, nonetheless a key metaphysical distinction between expressivists and realists. Dreier's suggestion is that the key to understanding the differences between expressivists and realists (specifically, nonnaturalists such as G.E. Moore) lies in their approach to explanation, and specifically to the explanation of moral judgments:

\footnotetext{
Suppose that Julia sincerely asserts the sentence, 'Knowledge is intrinsically good.' She believes, then, that knowledge is intrinsically good.

(J) Julia believes that knowledge is intrinsically good...

What the "explanation" explanation tells us is that the division between [Gibbard and a non-naturalist realist such as G.E. Moore] must lie in their differing explanations of (J). According to a Moorean, $(\mathrm{J})$ must consist in Julia's standing in a certain doxastic relation to goodness... By contrast, Gibbard's expressivist account will explain (J) by reference to the sort of planning state Julia is in: perhaps she has decided to include knowledge among her non-instrumental aims (Dreier 2004, 41).
}

Thus, according to Dreier, it is in the explanation of moral judgments that the distinction between expressivists and realists can be found.

As Matthew Chrisman (forthcoming) has argued, Dreier's suggestion seems illsuited as a general criterion for distinguishing realists from antirealists. Chrisman, in his argument, raises the parallel question of how the cosmological realist, and the cosmological antirealist, ought to approach the explanation of the following judgment:

(K) Joey believes that the planet Krypton is made of kryptonite.

It is unlikely that either the cosmological realist or the cosmological antirealist would want to make an appeal, here, to the nature of the planet Krypton in explaining the 
genesis of this belief. Thus, in the explanation of this sort of judgment, there is no distinction between the cosmological realist and the cosmological antirealist. In light of this, it seems hard to see how Dreier's account can be generalized.

A similar problem to the one cited by Chrisman arises in the case of explaining moral judgments. Consider Dreier's original example, of Julia who believes that knowledge is intrinsically good. Perhaps she reached this conclusion because she heard it in a lecture given by an especially charismatic professor. It is not a conclusion she reached on her own, and if there be such a thing as intuition of the good, she has never taken the time to engage in it herself. It seems that, on a realist or an expressivist view, the proper explanation of her judgment would tell us more about the charismatic professor, and her effect on people, and very little about the ontological status of goodness. It does not, thus, seem that the explanation of judgment provides us with a clear criterion for marking the distinction between expressivists and realists.

I think that there is an, however, important grain of truth in Dreier's suggestion, one that is helpful to understand the distinctive metaphysical commitments of expressivists. This is in the suggestion that explanation is key for understanding the distinctive views of expressivists. I contend that, rather than focusing on the explanation of judgments, the key metaphysical element of expressivism is a view of the explanatory status of properties. While minimalism suggests that expressivists should accept the existence of moral properties (and facts), explanatory considerations mark the distinction between expressivists and realists. These considerations show how expressivism contrasts with the views of naturalistic and nonnaturalistic forms of moral realism. Explanation helps to cash out the expressivist denial of the existence of "irreducible," "essential," or "specifically normative" properties.

The expressivist view of the explanatory status of properties is best understood in terms of a basic fact about explanation-explanation is asymmetric. There is a distinction between an explanans and an explanandum: the explanans explains the explanandum, but not vice versa. We can use this basic fact about explanation to mark a distinction between kinds of properties: "explanans" properties, properties that provide explanations for other kinds of properties, "explanandum" properties. These are relative notions: a property serves as an explanans with respect to a given explanandum property. Understanding the views of expressivists requires seeing how the expressivist would situate moral properties in a kind of hierarchy of properties, defined in terms of explanans and explanandum 
properties. The explanandum properties could be thought of as being at a higher level on an explanatory hierarchy than the explanans properties ${ }^{3}$.

One aspect of the expressivist view of moral properties is the aspect noted by Dreier: moral properties do not serve, on the expressivist view, as explanans properties for moral judgments. Another aspect of the expressivist view, one that marks a distinction between expressivists and naturalistic realists like Nicolas Sturgeon (1985), is that expressivists do not make appeal to moral properties as explanans properties in accounts of action: The naturalistic approach favored by Sturgeon, explaining Hitler's actions based on the causal explanatory role of Hitler's depravity, would be rejected on the expressivist view, for it makes an unnecessary "essential" appeal to moral properties. The best explanation of Hitler's actions would be based not on the depravity of Hitler, but rather on facts regarding Hitler's psychology and attitudes. Related to this matter, and to the debate between Sturgeon and Gilbert Harman, the expressivist would also deny the moral properties could serve as explanans properties in accounts of observation. To cite Harman's famous example, the expressivist explanation of why a suitable observer would observe that setting a cat on fire is wrong would not be one that makes an appeal to the wrongness of the act. To sum these points up, the denial of there being any "essential," or "specifically normative" properties is best understood, in part, as denying a role as explanans properties to moral properties.

This denial of a basic explanatory role to moral properties might still not be thought mark out a clear distinction between expressivists and realists, for while naturalistic realists are committed to the idea that moral properties are explanans properties, properties that play an explanatory role in accounting for judgment or action, "non-naturalistic" realists such as G.E. Moore and Russ Shafer-Landau make no such claims about the explanatory status of moral properties. The non-naturalistic view is fully consistent with moral properties not being explanans properties, in the

\footnotetext{
${ }^{3}$ It is possible for two different properties to serve as explanans properties for each other. If this is the case, it might be helpful to think of such properties as being on the same level on an explanatory hierarchy, but nonetheless bearing explanatory relations to each other. I will call this phenomenon 'lateral explanation.' To cite a simple example, pain might provide an explanation for depression, while depression may also provide an explanation for feelings of pain. If this is the case, than pain and depression are each explanans properties with respect to the other, and on the same level of an explanatory hierarchy. That such lateral explanations exist does not undermine the use of an explanatory hierarchy to mark distinctions between views. For if a reductionist identity theory is correct, it would be correct to think of neural properties as being the explanans for each pain and depression. So, even if pain and depression are on the same level of the explanatory hierarchy, each could also be thought of as being at one level higher than neural properties.
} 
sense explained above. This might cause further doubts as to whether the expressivist offers a distinctive metaphysical position.

There are two key differences, also best understood in explanation, between nonnaturalistic views and expressivism. First, on an intuitionist view such as Moore's, moral properties are explanans properties, given that the existence of moral properties is an essential element in the explanation of moral intuitions. On intuitionist views, moral properties are explanans properties for intuition properties. Expressivists, who are skeptical of moral intuition, will deny this intuitionist claim: there are no moral intuitions, hence no need to make appeal to moral properties in the explanation of intuitions. A second key aspect of non-naturalism is that moral properties are "sui generis": they cannot be accounted for in terms of naturalistic properties. Shafer-Landau, in his account, contends that moral properties supervene upon natural properties, but there is no explanation whatsoever of how this is the case-he suggests that the relation between the moral and the natural on his view is similar to the relation between the mental and the physical on Malebranche's occasionalist theory. "The present view ... requires something on the order of divine intervention to explain the intimate connection between something's moral status and its natural features" (Shafer-Landau 2003, 78). This view is not one that is shared by the expressivist - as Simon Blackburn has argued (Blackburn 1971, 1984, 1986), a key advantage of expressivism is in its demystification of the supervenience of the moral upon the physical world. This explanation of the moral in terms of the natural world rests on appeal to moral attitudes-on the expressivist view, moral properties are explained in terms of moral attitudes, and hence are not sui generis. This is not to say that moral properties are identical to attitude properties: the latter can serve as an explanation for the former without the two kinds of property being identical. Blackburn's idea that moral properties are "projected" on to the world, and Gibbard's more recent theory that morality is accounted for in terms of states of planning, are instances of this sort of approach. We can summarize this aspect of expressivism by saying that expressivism allows for moral properties to be "explanandum" properties.

Thus there is a metaphysical view distinctive of expressivism. Unlike the naturalistic realist, the expressivist denies that moral properties serve as explanans properties for judgments, acts, or observations. Unlike the intuitionist, expressivists do not claim that moral properties serve as explanans properties for moral intuitions. Last, but not least, the expressivist does not hold the non-naturalist view that there moral properties are not, in some way, explanandum properties-there is an explanation of moral properties in terms of moral attitudes. I will summarize this metaphysical aspect of expressivism, throughout the rest of the paper, by saying that 
expressivists are not committed to robust moral properties, where a robust property is either (a) an explanans property in the relevant sense or (b) sui generis. The expressivist view denies both of these claims, holding the view that moral properties are nonrobust.

\section{Expressivism and the Error Theory}

While there is, in light of these considerations, an expressivist position distinct from realism regarding the metaphysics of moral properties, there remains a question of whether expressivists are able to distinguish their view of these matters from other anti-realist positions, such as the error theory of John L. Mackie (1977). As noted above, Wright considers the minimalist approach to truth a source of concern not only for expressivists, but also for error theorists as well. Wright charges "the errortheorist, like John Mackie on ethics... will have his work cut out to make the charge of global error stick..." (Wright 1996, 864). This raises two issues. The first, beyond the scope of the present paper, is whether or not the case for the error theory is correct. The second issue raised by Wright's concern is the issue of how expressivism might differ from the error theory. One might worry that the minimalist approach to properties discussed above fails to distinguish among these anti-realist views.

This worry is unfounded. The minimalist property schema provides sufficient materials to distinguish the expressivist from the error theorist. One of the key commitments of the error theorist, unlike the expressivist, is the view that all moral claims are in fact false. Moral claims purport, according to Mackie, to refer to a realm of objective moral properties. These moral properties, Mackie argues, do not exist. As Mackie writes, the error theory is the view that "although most people in moral judgements implicitly claim, among other things to be pointing to something objectively prescriptive, these claims are all false" (Mackie 1977, 35).

This is a more radical position regarding moral ontology than the ontological position of the expressivist. If the arguments presented above are correct, expressivists ought to claim that moral properties do in fact exist, but that such properties are not robust explanatory properties. The error theorist would part company with the expressivist by denying the existence of moral properties of any sort, explanatory or nonexplanatory. It is worth noting that the minimalist property schema does not commit the error theorist to the existence of moral properties. The schema is as follows:

For any object $x, x$ has the property of being $F$ if and only if $x$ is $F .(1993,74)$

Given that, for any moral predicate ' $F$ ', claims of the form ' $x$ is $F$ ' are all false on the error theoretical view, there need be no commitment to moral properties on the error 
theoretical view. In other words, by denying all claims of the form ' $x$ is $F^{\prime}$ where ' $F$ ' is a moral predicate, the error theorist can also deny that any object whatsoever has a moral property. This kind of antirealism is also consistent with the minimalist property schema. Hence we can use minimalism about properties to distinguish between error theorists and expressivists.

To sum up the points made so far, what distinguishes expressivists both from moral realists and from error theorists is the distinctive account offered by expressivists of the metaphysics of moral properties. Given the relevance of these ontological claims, and of the expressivist commitment to a distinct view of the metaphysics of moral properties, it would not be correct to hold, as Wright does, that the only significant matter of dispute between the expressivist and the moral realist is over the attribution of truth to moral statements. Perhaps, however, implicit in Wright's argument is the claim also made by Boghossian, that expressivism's commitment to a certain view of truth renders it incompatible with minimalism. In the quote from Wright 1996, it is worth noting that Wright presents as the entire definition of expressivism the claim that moral discourse does not "really deal in truthevaluable contents."

The position presented by Boghossian and Wright, according to which minimalism and expressivism are incompatible, is based on a particular account of expressivism. This account reflects the commitments of those philosophers who first articulated protoexpressivist views, such as Hume and Ayer. It is not often noted that these philosophers had accounts of truth and meaning that led them to conclude that the expressivist should refrain from claiming that moral utterances are straightforwardly true or false. It is also odd, given the amount that has been written over the course of the $20^{\text {th }}$ century and into the $21^{\text {st }}$ century on expressivism and its forbears, that Boghossian and Wright, in the arguments they present, implicitly take the commitments of Hume and Ayer as representative of the entire expressivist tradition. As I will discuss in the following two sections, Hume drew this conclusion based on the conjunction of his views on morality and a correspondence theory of truth, and Ayer drew this conclusion based on the conjunction of his views on morality, a redundancy theory of truth, and a verificationist semantics. The minimalist who rejects the correspondence theory of truth and the verificationist theory of meaning need not draw the same conclusions as Hume and Ayer.

\section{Hume, Correspondence Truth, and the Denial Thesis}

The metaethical theory on which I have focused in this paper, expressivism, is indebted to the account of morality in David Hume's philosophy, especially the 


\section{2 | Fritz McDonald}

great work A Treatise of Human Nature. In the Treatise, Hume argues for the view that moral attitudes are neither true nor false. Thus Hume, one of the ancestors of contemporary expressivism, was committed to the Denial Thesis. However, unlike more recent philosophers, Hume makes it clear that this position on morality is a consequence of two distinct theories: a metaphysical position on the nature of moral sentiments, and a theory of truth, a version of the correspondence theory.

In the Treatise, Hume accounts for moral attitudes in terms of the passions, or emotions. Only a passion can move a person to act, according to Hume, and so any moral decision-making have as its basis certain passions. The passions, according to Hume, are dependent not upon the world, but on the mind of the individual making the moral decision. As Hume writes in the Treatise,

\footnotetext{
Truth or falshood consists in an agreement or disagreement either to the real relations of ideas, or to real existence and matter of fact. Whatever, therefore, is not susceptible of this agreement or disagreement, is incapable of being true or false, and can never be an object of our reason. Now 'tis evident our passions, volitions, and actions are not susceptible of any such agreement or disagreement; being original facts and realities, compleat in themselves, and implying no reference to other passions, volitions, and actions. 'Tis impossible, therefore, they can be pronounc'd either true or false, and be either contrary or conformable to reason (Hume 2000, 295).
}

If truth or falsehood consists of agreement between representations in the mind and mindindependent objects, as it does on Hume's formulation of the correspondence theory, then it follows that Hume must deny that moral attitudes that consist in passions are capable of being true or false.

Hume's argument for the claim that moral attitudes cannot either be true or false may be summarized as follows:

P1: (Semantic premise) Truth or falsehood consists in agreement or disagreement of ideas with entities resembling the ideas.

As Hume states the theory, "contradiction" of truth "consists in the disagreement of ideas, consider'd as copies, with those objects, which they represent." (Hume 2000, 267).

Such contradiction is evident in cases when one believes, for example, in a dream that one is sitting at a desk, but no desk corresponds to the idea one has, the mental representation of a desk.

P2: (Metaphysical premise) There are no mind-independent moral objects, but rather only passions and volitions in the mind.

Hume expresses this point as follows:

A passion is an original existence, or, if you will, modification of existence; and contains not any representative quality, which renders it a copy of any other existence or 
modification. When I am angry, I am actually possest with the passion, and in that emotion have no more a reference to any other object, than when I am thirsty, sick, or more than five foot high (Hume, 2000, 266).

From P1 and P2 it follows that:

C: Moral attitudes are neither true nor false.

Hume implicitly draws the conclusion as follows in a general statement regarding the passions: "'Tis impossible, therefore, that this passion can be oppos'd by, or be contradictory to truth and reason" (ibid., 266-67).

With the original argument for the Denial Thesis in hand, it ought to be clear that Hume's argument is not sound if we reject a correspondence theory of truth. If we reject premise P1, the correspondence theory, in favor of a minimalist account of truth, it is clear that the conclusion $C$, the Denial Thesis, does not follow from Hume's argument. The Denial Thesis follows from this Humean argument only on the assumption that Hume's fairly simplistic correspondence theory of truth is correct.

\section{Ayer, Verificationism, and the Denial Thesis}

As I have discussed in detail above, in the section Are Minimalism and Expressivism Compatible?, one of the influential arguments for incompatibilism is presented in response to the views of Ayer. Paul Boghossian contends that Ayer failed to recognize the "tension" between the redundancy theory of truth and an expressivist account of ethics (Boghossian 1990, 163). Given that this debate has been framed in response to Ayer's views, it is not solely of historical importance to investigate whether there was in fact a tension in the views Ayer presented in Language, Truth, and Logic. In fact, when Gibbard describes his view in Wise Choices, Apt Feelings as a "non-cognitivistic" one, given that "according to it, to call a thing rational is not to state a matter of fact, truly or falsely," he cites in a footnote his debt to Ayer's "noncognitivistic treatment of moral language..." (Gibbard 1990, 8).

A closer inspection of Ayer's account reveals that Boghossian is incorrect regarding the supposed tension in Ayer: The views presented in Language, Truth, and Logic are fully consistent, and Ayer's case for the Denial Thesis rests on a view that minimalists need not accept, a verificationist account of meaning. Ayer formulates his version of the redundancy theory of truth in terms of propositions. Propositions are the bearers of truth and falsity. Ayer writes: 


\section{4 | Fritz McDonald}

That this is an important aspect of Ayer's view will become clear when we consider his view on whether moral utterances involve propositional content.

On Ayer's account, the addition of the words 'is true' to an assertion does not change the content of the original assertion. These words are redundant. "When one says that the proposition 'Queen Anne is dead' is true, all that one is saying is that Queen Anne is dead" (cf., 88). There are many disadvantages to such a redundancy theory that are not shared by other deflationary accounts such as minimalism: it is quite hard to imagine how to formulate useful generalizations about true statements on such a view.

What has not been noted sufficiently in the discussion of Ayer is that in his discussion of moral language, Ayer makes a quite strong, rather implausible claim regarding moral judgments. Ayer notes a difficulty with accounts of morality which make appeal to rational intuition as the basis for moral knowledge. If we take such an intuitionist view seriously, how do we determine which purported moral intuitions are the correct ones? If one person claims to know by intuition that sacrificing the life of one person to save the lives of five others is right, and another person claims to know by intuition that sacrificing the life of one person to save the lives of five is wrong, how do we decide which intuition is the correct one? It seems we have no way of verifying the appeals to intuition involved in ethical judgment.

In the discussion of Ayer by Boghossian and the citation of Ayer by Gibbard, it is not noted that, in addition to a redundancy theory of truth, Ayer held a verificationist account of meaning. On Ayer's account, an expression is meaningful only if it can be verified. Any expression that is not verifiable does not express a proposition, but rather a mere "pseudoproposition" that is not capable of being true or false. It is due to Ayer's view that moral judgments are unverifiable-hence they express "pseudopropositions" - that Ayer held that moral utterances are incapable of being true or false. Boghossian overlooks this verificationist constraint-With such a constraint in place, it is clear that Ayer's views on morality and truth are consistent.

As was the case with Hume's argument for the denial thesis, it is very important to note that the argument in Ayer from expressivism to denying that moral utterances are capable of being true or false rests on assumptions the contemporary deflation nist need not share. A minimalist about truth who holds a use-theoretical account of meaning would reject a crucial step in Ayer's argument. Not being a verificationist, the use-theorist can reject Ayer's claim that moral utterances express only pseudopropositions. Thus neither of the historical arguments from expressivism to the Denial Thesis ought to move a philosopher 
convinced of expressivism and deflationism to hold that moral utterances are incapable of being true or false.

\section{Minimalism, Expressivism, and the Attribution of Truth}

The view that moral utterances are not straightforwardly true is a theory that is not required for a formulation of an expressivist theory. As I have shown in the sections above, Hume and Ayer drew the conclusion that moral utterances are neither true nor false from their commitment to, for Hume, a correspondence theory of truth, and for Ayer, a verificationist theory of meaning. A philosopher who holds neither of these theories will naturally draw different conclusions regarding the truth and falsehood of certain utterances.

Regardless of the failure of the traditional expressivist arguments to motivate minimalists to accept the Denial Thesis, one can still ask whether this thesis is nonetheless an essential element of the expressivist theory. In order to see whether this is the case we must look to the arguments that have motivated expressivism as well as the details of the theory. If neither the motivations behind expressivism nor the details of the theory is in conflict with minimalism, then it is clear that the case for incompatibilism is a failure.

The crucial motivations behind expressivist views, historically, are as follows. First, expressivists are motivated by a view on the metaphysics of morality. Expressivists have denied, as I have explained above, the existence of robust moral properties. The other crucial motivation behind expressivism is that expressivists want an account of moral language that can explain the close tie between moral attitudes and motivation. This aspect of expressivism has a historical lineage beginning with the work of Hume cited above, particularly Hume's claim that the passions alone can motivate, and reason, without a passion, cannot. Due to this account of motivation, expressivists have claimed that moral utterances serve the purpose of expressing some mental state that plays a role in leading to motivation, such as an emotional reaction, a desire, acceptance of a norm, or what Gibbard (2003) calls planning.

The minimalist account of truth shows the possibility of a coherent position that is consistent with these motivations behind expressivism while allowing for the possibility that moral utterances are capable of being true or false. It is possible for the expressivist to hold the view that there are no robust moral properties as well as the view that moral utterances serve to express desires (or similar mental states) independently of any commitments on a particular account of truth. 
There is no inconsistency between holding that moral utterances are straightforwardly true and holding that there are no robust properties picked out by moral predicates such as 'right,' 'just,' 'good,' and 'evil.' It should be clear that one's stance regarding the existence robust moral properties and facts is not automatically settled by answering the question of whether truth ought to be attributed to moral utterances. On the minimalist theory, truth could be attributed to an utterance such as 'Killing is wrong' regardless of whether wrongness is a robust property. All that is required is that wrongness is a property according to the minimalistic property schema. What does determine whether or not truth should be attributed to utterances of 'Killing is wrong' is whether killing is wrong. If wrongness is predicated of killing, it is not necessarily the case that a robust property is being attributed to killing. It is a separate matter whether we can make an explanatory appeal to the wrongness of killing to explain whether the wrongness of such acts is what causes people not to commit them, or whether it is the wrongness of killing that explains our knowing that killing is wrong. One could hold that killing is wrong yet deny any such explanatory claims. So, if wrongness is attributed to killing, then (by the deflationary schema), there is a true attribution of wrongness to killing. This does not, for reasons discussed above, imply that wrongness need be a robust property.

The issue of whether moral attitudes consist of beliefs only, desires only, or some combination of the two is independent both of this metaphysical issue and the matter of whether truth ought to be attributed to moral utterances. The major question regarding moral psychology is the question of what sort of mental events are involved in moral thinking. Can one, as Hume (2000) famously claimed, never be motivated by a belief alone, without any passion? If so, do all moral attitudes essentially involve emotions or desires? On the other hand, given the resemblance between certain kinds of moral talk and other language that serves to express beliefs, should we hold that moral claims generally express beliefs? Or, is it possible that our moral attitudes are some combination of both beliefs and desires?

Is this issue of moral psychology, the issue of the nature of moral attitudes, an issue that is inseparable from the issue of moral metaphysics? Is it possible to combine distinct views on moral psychology with various views on metaphysics? Can we only have moral beliefs if moral utterances are straightforwardly true and there are robust moral properties? Would claiming that there are merely moral desires but no moral beliefs preclude the attribution of straightforward truth to moral utterances, and lead us to deny the existence of robust moral properties?

There are three possible views one could hold regarding moral attitudes: (1) Moral attitudes consist in desires alone; (2) Moral attitudes consist in beliefs and desires; (3) Moral attitudes consist in beliefs. I will consider views 2 and 3 first. On 
either of these views, it is clear that holding such a view of moral psychology does not automatically settle the issues of moral truth or moral metaphysics. It is possible to have beliefs about both robust properties and nonrobust properties. Consider other properties that may or may not play a basic explanatory role, such as color. It is a subject of debate in philosophy whether colors are objective properties, properties that can be invoked in explanations of color perceptions, or whether color properties are subjective properties, projections from perceivers onto the world. In either case, it is clear that we can have beliefs about colors: We can believe a certain object is blue. Such a belief is true or false depending on the circumstances. Therefore, one can combine the view that there are color beliefs with the view that colors are nonrobust properties as well as the view the colors are robust properties.

What if view 1 , the theory that moral attitudes consist in having desires, is correct? Many philosophers who have been inclined toward such a view have had difficulty explaining the apparent belief-like nature of moral attitudes. It seems intuitive to describe a person who is against the genocide in Darfur as a person who believes the genocide in Darfur is wrong. For this reason, philosophers such as Simon Blackburn have acknowledged that moral attitudes, while essentially desires, often have belief-like characteristics. Such states are "quasi-beliefs" or "pseudobeliefs": While they are not genuine beliefs, they are sufficiently belief-like to play a similar role.

If one is sufficiently motivated by the Humean considerations cited above to hold view 1, and deny the possibility of any moral beliefs, then one can appeal to such a notion of "quasi-belief" to articulate a range of positions on moral truth and moral metaphysics. Perhaps, as A.J. Ayer claims, moral attitudes are not sufficiently belief-like to have propositional contents; hence there are no moral truths. Perhaps, as Blackburn claims, moral attitudes are similar enough to beliefs that we can consider such attitudes capable of being assessed as true or false.

In a similar vein, if a philosopher who denies the existence of genuine moral beliefs holds that moral commitments are nonetheless "quasi-beliefs," such a philosopher can take a range of positions on whether such "quasi-beliefs" denote properties. Perhaps these "quasibeliefs" denote robust properties or perhaps they may denote non-robust properties. There is a range of options here, and the position one takes regarding these options is not settled simply by claiming that moral attitudes consist of desires alone. Insufficient thought has been given to the array of positions in logical space.

In light of this consideration of the central metaphysical and psychological thesis of expressivism, it ought to be clear that there is no incompatibility between minimalism and these theses. 


\section{Can this Dispute Be Resolved?}

It is possible that at this point in the debate, due to the fact that expressivists have traditionally assumed that moral utterances are incapable of being true or false, a philosopher could deny that the position I sketched above is in fact an expressivist position. One would have to ask at this point whether this is a substantial dispute regarding the motivations behind expressivist theories, and the details of the theory as spelled out by its proponents, or whether this is a purely verbal dispute about the proper use of the philosophical term 'expressivism.'

Such a philosopher might present a convincing reason for thinking that the position I have sketched above is not an open option. If this were to happen, such an argument would be an argument about the substance of the issue, and would not be a purely verbal dispute. If, on the other hand, a philosopher does not give a reason to think that this position is not an open option, and merely insists on a certain restricted use of the philosophical term 'expressivism,' then this philosopher making a purely verbal point. If this were to happen, I would simply cede the term 'expressivism' to my opponent. My concern in this paper has been to discuss the relationship between deflationary and minimalist theories of truth and a metaethical account of the kind proposed by Stevenson, Gibbard, Blackburn, and other philosophers. If necessary, I could phrase the question posed in this paper as the question of whether an account of the kind presented by these philosophers is consistent with deflationism and minimalism. Another approach, proposed by Horwich (1993), would be to suggest that an account of this kind is a revision of expressivism, a revision that has advantages over its traditional expressivist predecessors. Either strategy, it seems, would successfully answer this worry. The most reasonable formulation of an expressivist theory of ethics would embrace a minimalist account of truth, and it ought to be clear that none of the incompatibilist arguments would successfully prevent the marriage of expressivism and minimalism.

\section{Literature}

Ayer, A. J. 1936. Language, Truth, and Logic. London: Dover.

Blackburn, S. 1971. Moral Realism, in Blackburn 1993. 1984. Spreading the Word. Oxford: Oxford University Press. 1986. Supervenience Revisited, in Blackburn 1993.

. 1988. How to be an Ethical Antirealist, in S. Darwall, A. Gibbard, and P. Railton, 1997: 167-178. 
_. 1993. Essays in Quasi-Realism. Oxford: Oxford University Press. . 1998. Ruling Passions: A Theory of Practical Reason. Oxford: Clarendon Press.

Boghossian, P. 1990. The Status of Content. Philosophical Review 99: 157-84.

Chrisman, M. 2005. Thinking How to Live. Ethics 115: 406-411.

Chrisman, M. [forthcoming, 2012]. Expressivism, Inferentialism, and Saving the Debate. Philosophy and Phenomenological Research.

Divers, J. and Miller, A. 1994. Why Expressivists about Value Should Not Love Minimalism about Truth. Analysis 54: 12-19.

Darwall, S., Allan G., and Railton P. 1997. Moral Discourse and Practice: Some Philosophical Approaches. New York: Oxford University Press.

Dreier, J. 2004. Meta-ethics and the Problem of Creeping Minimalism. Philosophical Perspectives 18: 23-44.

Gibbard, A. 1990. Wise Choices, Apt Feelings. Oxford: Oxford University Press.

_. 2003b. Thinking How to Live. Cambridge, Mass.: Harvard University Press.

Harman, G. 1977. The Nature of Morality. New York: Oxford University Press.

Horwich, P. 1993. Gibbard's Theory of Norms. Philosophy and Public Affairs 22: 67-78.

_. 1994. The Essence of Expressivism. Analysis 45: 19-20. . 1998. Truth. Oxford: Oxford University Press.

Hume, D. 2000. A Treatise of Human Nature. Ed. by D. F. Norton and M. J. Norton. Oxford: Oxford University Press.

Lenman, J. 2003. Disciplined Syntacticism and Moral Expressivism. Philosophy and Phenomenological Research 66: 32-57.

Mackie, J. L. 1977. Ethics: Inventing Right and Wrong. London, England: Penguin Books.

Shafer-Landau, R. 2003. Moral Realism: A Defence. Oxford: Clarendon Press.

Stevenson, Ch. 1937. The Emotive Theory of Ethical Terms. Mind 46: 14-31.

Sturgeon, N. 1985. Moral Explanations, in Shafer-Landau and Cuneo 2007: 337-352.

Wright, C. 1985. Spreading the Word. Mind 94: 310-19.

_. 1992. Truth and Objectivity. Cambridge, Mass.: Harvard University Press. . 1996. Precise of Truth and Objectivity. Philosophy and Phenomenological Research 56: 863-868. 
Fritz McDonald (Oakland University)

\title{
Minimalism and Expressivism
}

\begin{abstract}
There has been a great deal of discussion in the recent philosophical literature of the relationship between the minimalist theory of truth and the expressivist metaethical theory. One group of philosophers contends that minimalism and expressivism are compatible, the other group contends that such theories are incompatible. Following Simon Blackburn (manuscript), I will call the former position 'compatibilism' and the latter position 'incompatiblism.' Even those compatibilist philosophers who hold that there is no conflict or tension between these two theories-minimalism and expressivism-typically think that some revision of minimalism is required to accommodate expressivism. The claim that there is such an incompatibility, I will argue, is based on a misunderstanding of the historical roots of expressivism, the motivations behind the expressivist theory, and the essential commitments of expressivism. I will present an account of the expressivist theory that is clearly consistent with minimalism.
\end{abstract}

Keywords. Minimalism; Expressivism; Truth; Metaethics; Gibbard, Allan; Blackburn, Simon; Realism; Anti-Realism; Quasi-Realism

Citations. Reference this paper as: McDonald, F. (2012). Minimalism and Expressivism. Ethics in Progress Quarterly, Volume 3, Issue 1, pp. 9-30, available online at ethicsinprogress.org. 